\title{
Simulation of Ice Growth in Process of Liquor Evaporation- Freezing by Fractal Theory
}

\author{
Gao Penghui", Zhou Xingye, Zhang Donghai and Wang Yijiang
}

School of Architecture and Civil Engineering, China University of Mining and Technology, Xuzhou, Jiangsu, 221116, China

\begin{abstract}
Considering complexity in process of the liquor's evaporation-freezing and irregularity on the liquor surface, generating and developing model of ice on liquor surface was proposed by humidity difference based on fractal theory and diffusion limited aggregation model (DLA). The effect of gas flow velocity and humidity difference between gas and liquor surface on generating and developing of ice above liquor surface were analyzed by numerical simulation. The results showed that the fractal method could simulate the process generating and developing model of ice above liquor surface. It provided the new idea and method for the study of the liquor evaporation-freezing and ice growth.
\end{abstract}

Keyword: Evaporation-freezing, fractal simulation, ice.

\section{INTRODUCTION}

In 1970s B. Mandelbort proposed fractal Theory providing an effective ways to solve the difficulties of traditional European Geometry on quantitative description of the irregular shape and complex structure, which has become a powerful tool to deal with the natural and engineering irregular problems, in addition, its application to almost all areas of the natural sciences. Wu Xiaomin [1] used fractal theory to establish the fractal model of early frost growth process, discussing the influence by air velocity and surface contact angle on the frost layer growth process. Shen Zhengwei [2] did the fractal studies on boiling heat transfer process, applying the concept of fractal dimension in the analysis of nonlinear problems of boiling heat transfer to reveal the complexity of boiling heat transfer. Du Yanxia [3] studied the micro-structure of aircraft icing's fractal research by fractal theory, analyzed the relationship between ice type fractal dimension and icing conditions. Yao SC [4] and Libbrecht [5] studied in porous media, crystals, polymers and other aspects by the fractal theory. Gao Zhenhui [6] used fractal method to predict the trend of Bohai sea icing and achieved satisfactory results.

From the current researches, Fractal Theory had applied in frost crystal growth and ice micro-structural aspects, but there are no the researches on ice body formation and development. This article would analyze and discuss the process base on the fractal diffusionlimited aggregation theory. Considering the liquor evaporation-freezing process by humidity difference

*Address correspondence to this author at the School of Architecture and Civil Engineering, China University of Mining and Technology, Xuzhou, Jiangsu, 221116, China; Tel: +86(516)83882193; Fax: +86(516)83885478;

E-mail: gaopenghui2004@126.com

E-ISSN: 1929-6002/14 driven at $0{ }^{\circ} \mathrm{C}$ environment (Freezing is driven by humidity difference at the gas-liquid interface, having energy saving and environmental protection features in this process), Ice formation, the irregularity development and self-similarity accord with the characteristics of fractal growth. Based on the experimental study, simulation ice formation and development process on the liquor surface were discussed to know the effect by different factors on the ice formation and development and to deepen the understanding of the freezing mechanism. It will be favor to the study of freezing and refrigeration in the energy application efficiently.

\section{LIQUOR SURFACE'S FRACTAL CHARACTE- RISTIC OF ICE FORMATION AND DEVELOPMENT}

Ice formation and development is changing process from liquid to solid state, as ice form being irregularity and randomness, The Euclidean space theory still has greater difficulty in describing the icing. Traditional theory in describing freezing process, usually uses heat and mass balance theory, and describes the ice formation and development as a uniform, single macroscopic change process, ignoring the randomness and disorder of ice formation and development of freezing process, which leads to the simulation results that is far from the real icing process.

As a whole of ice, the ice freezing form with different process leading to diverse shapes. In laboratory liquor's evaporation-freezing process, we used the Olympus CX21BIM - SET5 microscope and digital camera to observe ice generation and development, with reference [7] to the development of ice, icedevelopment process can be divided into three stages, which were shown in Figure 1a original ice, surface of the liquor at this time, there were produced scattered 


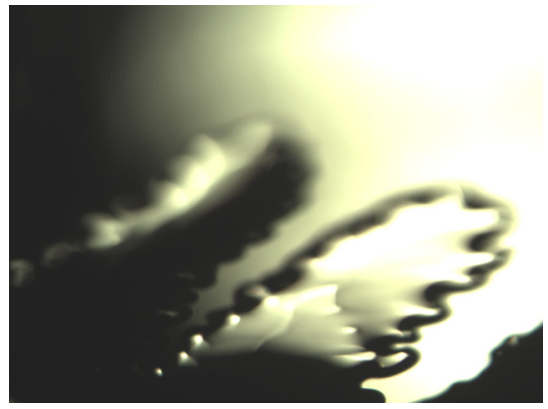

(a)

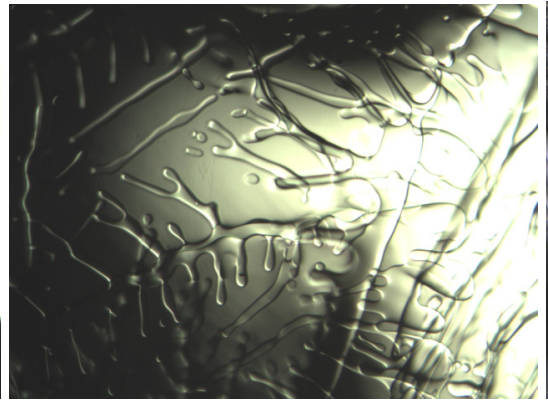

(b)

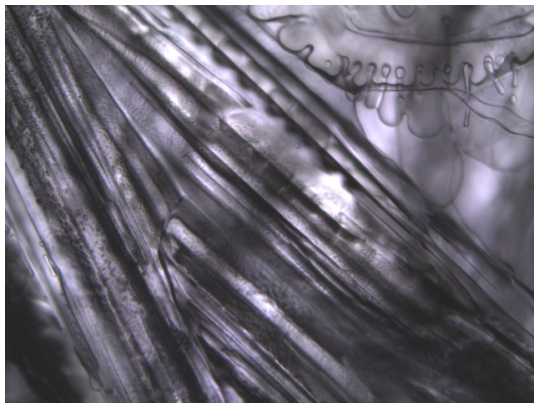

(c)

Figure 1: Different development phases of ice. (a) Original ice. (b) Ice hull. (c) Stress ice.

ice, mostly acicular, flaky, pasty or woolly; Figure 1b was ice hull, original ice was gone on freezing, on the surface ice of the liquor, and thickness of ice was thin, generally thinner than $0.5 \mathrm{~cm}$, easily broken; Figure 1c was stress ice, the ice formed on the basis of the ice hull of the liquor to continue to develop to be stress ice, and its thickness was more than $1.5 \mathrm{~cm}$.

Formation of ice in the development presented a similar cloud-expansion, in line with fractal characteristics of self-similarity and randomness. Figure 2 shows the ice microgram during the liquor's evaporation-freezing process, Figure $\mathbf{2 a}$ is the actual captured photograph, Figure $\mathbf{2} \mathbf{b}$ is through the enhancement, noise reduction and binary processing. Figure $\mathbf{2} \mathbf{b}$ shows the ice of liquor surface which has certain characteristics of skeleton by digitized photograph and which could simulate ice skeleton features to reflect ice developments.

Different from objects which traditional European theory described, the object has a non-integer fractal dimension [8], the fractal object exists the following relationship between dimension and measure:

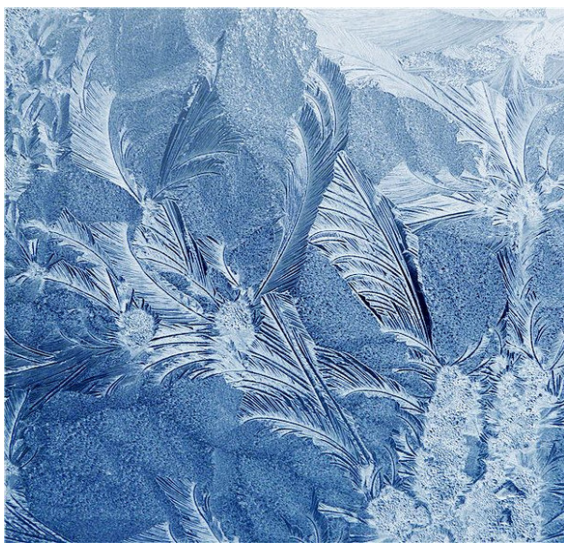

(a)

$$
M\left(L_{f}\right) \propto L_{f}^{d_{f}}
$$

Where, $M\left(L_{f}\right)$ is a measure of fractal objects; $L_{f}$ is measurement scales; $d_{f}$ is the fractal dimension. If $M\left(L_{f}\right)$ is a fractal length, $d_{f}<1$; if $M\left(L_{f}\right)$ is a fractal area, then $1<d_{f}<2$; if $M\left(L_{f}\right)$ is a fractal volume, then $2<d_{f}<3$.

Box-counting dimension method was used to solving the fractal dimension in Figure 2, the fractal dimension is $d_{f}=\lim _{\delta \rightarrow 0} \frac{\ln N_{\delta}(F)}{-\ln \delta}$.

Where $\delta$ is the side length of the square box; $N_{\delta}(F)$ for the side length $\delta$ of the box is intersected by the number of metric $F$. When $\delta \rightarrow 0$ 时, $N_{\delta}(F)$ logarithmic series increase with $\delta$ the decrease is boxcounting dimension. Actual computation can use $\ln N_{\delta}(F) \sim-\ln \delta$ to estimate the slope value. The change relationship between $N_{\delta}(F)$ and $\delta$ shown in Figure 3, whereby the fractal dimension $d_{f}=1.84$.

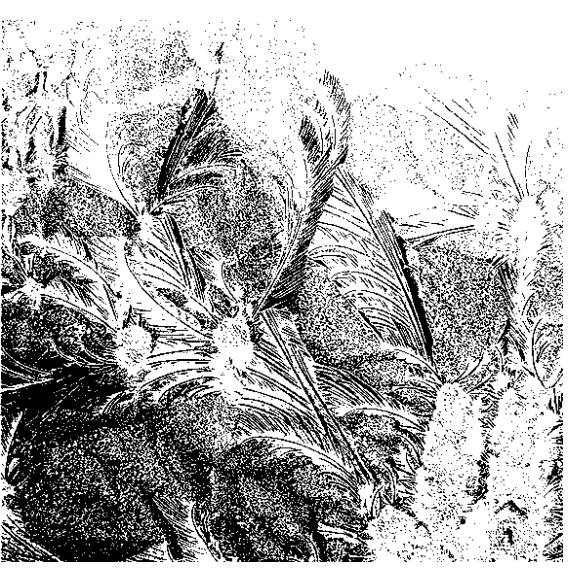

(b)

Figure 2: Framework characteristic of ice. (a) Original microgram of ice. (b) Disposed microgram of ice. 


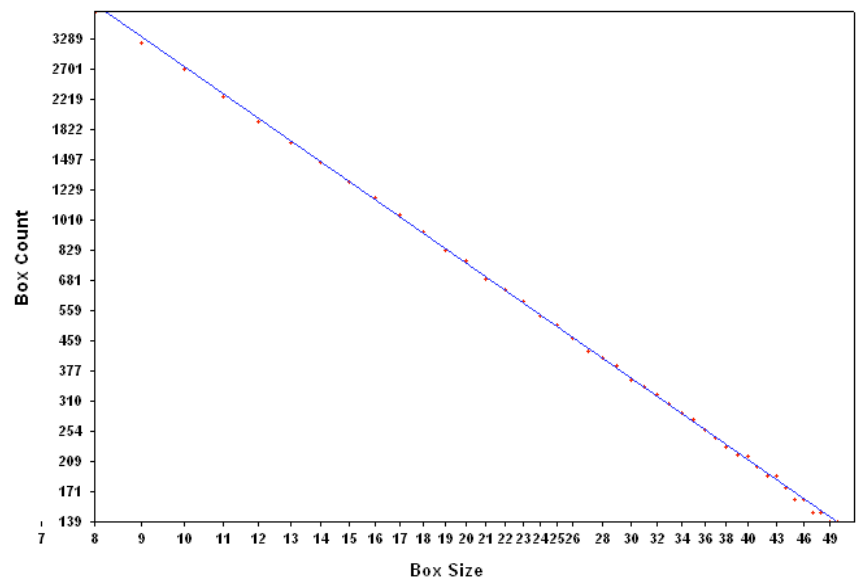

Figure 3: Relation between $N_{\delta}(F)$ and $\delta$.

In order to make clear the ice development tendency and reduce computational capacity by the humidity difference effect during the liquor evaporationfreezing process, combined with the ice skeleton characteristics, a fractal model was established in which ice framework was as simulation key element. Ice formation and development's various influential elements have been analyzed and studied to reveal its law which can provide theoretical guidance and reference for theoretical research and engineering applications.

\section{THE FRACTAL MODEL OF LIQUOR SURFACE ICE FORMATION AND DEVELOPMENT}

The ice formation and development is complex in liquor evaporation-freezing process, there are both diffusion transport process and environmental interference factors. So the interface of actual ice growth not only need to meet the diffusion equation, also satisfy the stability condition (at the interface, the tiny external disturbances can gradually decrease away with time extending over). It is suggested that a transport motion which is deduced separately by diffusion equations is not the necessary actual existence interface during the ice grow. Combined with skeletal features during the ice formation, development process and fractal characteristics, the model of diffusion-limited aggregation (DLA) is used to simulate during the ice growth process on liquor evaporationfreezing surface.

The model of diffusion-limited aggregation (DLA) [9] is an important one of the growth models in the fractal theory; the model can generate self-similar fractal structure with scale invariance by dynamics.

Based on DLA model and the characteristics of the liquor evaporation-freezing, the idea of simulation is:
(1) establishment of a specific region as the ice growth space; (2) the edge of the bottom is set to the initial location of ice formation and development; (3) simulation ice growth in the region is in accordance with the DLA model's growth mechanism, and conferring particle a certain speed to simulate ice growth of liquor surface with different airflow; (4) during the simulation, the humidity difference of the interface between air and liquor determines the number of particles released immediately each round; (5) complete the number of advance cycles and the program ends.

Set the simulation calculation process area to be $m \times n$ (pixels). The number of particles was released associated with the humidity difference every round in reference [10]. The relative humidity above liquor interface is $\phi$ for a given temperature $T$, then the number of circulating particles released each round is:

$$
N=m \times \phi
$$

Where $m=800, n=500$

\section{SIMULATION OF LIQUOR SURFACE ICE FORMATION AND DEVELOPMENT}

The ice generation and development is affected by many factors in liquor evaporation-freezing process, such as the flow velocity of air over the liquor, the humidity difference between liquor surface and airflow, the environment, etc. In order to clarify the factors above effecting liquor evaporation-freezing process by airflow humidity difference under $0{ }^{\circ} \mathrm{C}$ in the practical engineering, the humidity difference between liquor and interface, the flow velocity effecting on the ice formation and development were analyzed in liquor evaporationfreezing process.

When the humidity difference between liquor and air surface was $0.003 \mathrm{~g} \cdot(\mathrm{kg} \text { dry air })^{-1}$, the width of the liquor surface was $1.0 \mathrm{~m}$. The air flow velocity was $1.0 \mathrm{~m} / \mathrm{s}, 2.0 \mathrm{~m} / \mathrm{s}$ and $4.0 \mathrm{~m} / \mathrm{s}$, simulation and prediction of the ice formation and development on liquor surface were studied. Figure 4 showed the ice formation and development with the different gas flow velocity.

As can be seen from Figure 4, when the humidity difference between the liquor surface and air was a certain number, the air velocity had an obvious effect on the ice growth of liquor surface. In the same time, the larger flow velocity, the growth had more intense trends. The reason is that when the air velocity increases, strengthening evaporated mass transfer 

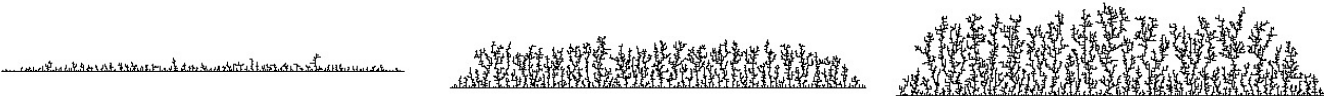

(a) gas flow velocity $1.0 \mathrm{~m} / \mathrm{s}$

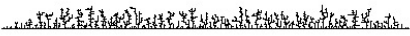
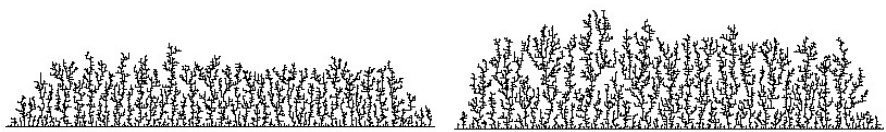

(b) gas flow velocity $2.0 \mathrm{~m} / \mathrm{s}$

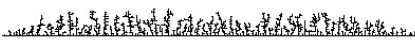
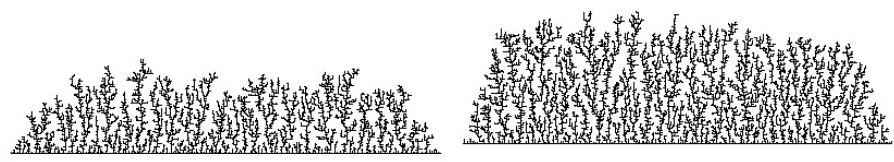

(c) gas flow velocity $4.0 \mathrm{~m} / \mathrm{s}$

Figure 4: Ice growth in different airflow velocity. (a) Time 1500s. (b) Time 3500s. (c) Time 5000s.

between the liquor and the interface of air, under the same conditions, would make more liquor be evaporated and frozen, so that the ice grows more intense. In engineering, the flow velocity can be enhanced the evaporation and freezing of liquor to increase the ice quantity.

When the air flow velocity was $2.0 \mathrm{~m} / \mathrm{s}$, the liquor surface width was $1.0 \mathrm{~m}$, respectively, the humidity difference between the liquor and the interface of air is $0.001 \mathrm{~g} \cdot(\mathrm{kg} \text { dry air })^{-1}, 0.002 \mathrm{~g} \cdot(\mathrm{kg} \text { dry air })^{-1}$ and 0.003 $\mathrm{g} \cdot(\mathrm{kg} \text { dry air })^{-1}$, simulation and prediction of the ice formation and development on liquor surface were studied. Figure $\mathbf{5}$ showes the ice formation and development with the different humidity difference.

As can be seen from Figure $\mathbf{5}$, the humidity difference between the air and the surface of liquor had an important effect on the liquor evaporation-freezing process. When the humidity difference between air and liquor surface increasing, the ice growth was more intense in the same conditions. Because the large humidity difference induced to evaporation mass transfer increasing between the air and liquor surface, it benefit liquor evaporation-freezing process. In the same humidity difference, with the extension of time, the surface of ice was gradually expanded. As a whole, the larger humidity difference at gas-liquid interface is in favor of the liquor evaporation-freezing and the method is feasible by increasing the humidity difference to enhance the process.

\section{CONCLUSIONS}

In this article, combined the experiment of the ice formation and development in the liquor evaporationfreezing process, based on the ice skeletal characteristics and fractal diffusion-limited aggregation (DLA) theory, fractal model was proposed by humidity difference, in which simulation core elements was ice skeleton. The intuitive, visual analysis and research about various elements which have affected on the ice

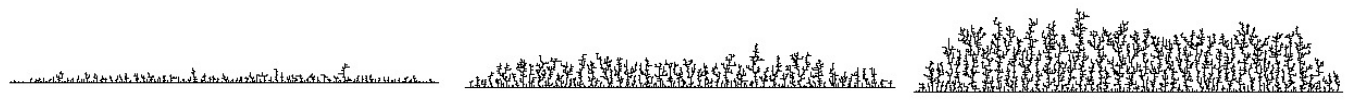

(a) humidity difference $0.001 \mathrm{~g} \cdot(\mathrm{kg} \text { dry air })^{-1}$

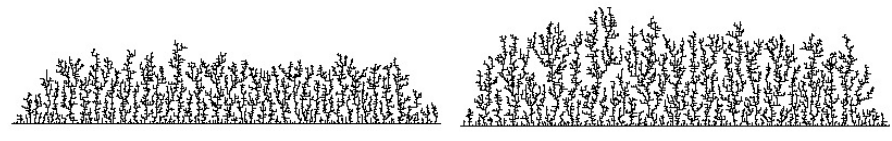

(b) humidity difference $0.002 \mathrm{~g} \cdot(\mathrm{kg} \text { dry air })^{-1}$

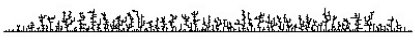

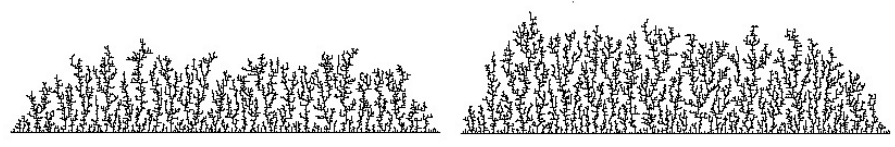

(c) humidity difference $0.003 \mathrm{~g} \cdot(\mathrm{kg} \text { dry air })^{-1}$

Figure 5: Ice growth in different humidity difference. (a) Time 1500s. (b) Time 3500s. (c) Time 5000s. 
formation and development were studied. The results showed that the humidity difference between air and liquor surface and flow velocity had an obvious effect on the ice growth during liquor evaporation-freezing process. In the engineering, increasing the humidity difference and the flow velocity could be better for the liquor evaporation-freezing process at $0 \quad{ }^{\circ} \mathrm{C}$ environment. Meanwhile it provided a new ideas and methods for ice science research that fractal theory was analyzed the ice growth.

\section{ACKNOWLEDGEMENTS}

The work was supported by the Chinese Foundation Committee of Nature and Science (Project No. 51106176), China Postdoctoral Science Foundation (Project No. 20110490042).

\section{REFERENCES}

[1] Xiaomin W, Hang J, Kerry MS, et al. Fractal theory frosting Numerical Simulation [J]. J Eng Thermophys 2010; 31(12): 2073-75.
[2] Zhengwei $\mathrm{C}$, Jun $\mathrm{W}$, Shen requirements. Fractal boiling heat transfer analysis [J]. Thermal Sci Technol 2004; 3(4): 369-72.

[3] Yanxia D, Ye-Wei G, Peng K, et al. Aircraft type microstructure features junction Ice Fractal study [J]. J Aerospace Power 2011; 26(5): 997-1002.

[4] Yao SC, Pitchum ani R. Fractal based correlation of forthe evaluation of thermal conductivities of fibrous com-posities [J]. Transport Phenomena Materials Process-Ing 1990; 146: 55-60.

[5] Libbrecht KG. The physics of snow crystals [J]. Re-ports on Progress in Physics 2005; 68(4): 855-95. http://dx.doi.org/10.1088/0034-4885/68/4/R03

[6] Will KC, Jianqiang Y, Shu FL. Fractal analysis methods in sea ice trend forecasting [J]. Marine Sci Bull 2003; 22(4): 6669.

[7] National Snow and Ice Data Center. Sea ice index [EB/OL] [2013-03-26]. http://earthobservatory.nasa.gov/Features/ Sealce/.

[8] Jizhong Z. Fractal [M]. Second Edition. Tsinghua University Press, Beijing 2011.

[9] Flowers Z, Tracy J. Fractal Theory and Its Applications[M] Science and Technology Press, Beijing 2011.

[10] Puxiu H. Frost layer growth process and theoretical analysis of experimental studies [D],Southeast University PhD thesis, Nanjing 2006. 